\title{
Birds of a "bad" feather flock together: The Dark Triad and mate choice
}

\author{
Peter K. Jonason ${ }^{\mathrm{a}, *}$, Minna Lyons ${ }^{\mathrm{b}}$, Alyson Blanchard ${ }^{\mathrm{b}}$ \\ ${ }^{a}$ University of Western Sydney, Australia \\ ${ }^{\mathrm{b}}$ University of Liverpool, England, UK
}

\section{A R T I C L E I N F O}

Article history:

Received 9 December 2014

Received in revised form 13 January 2015

Accepted 14 January 2015

\section{Keywords:}

Psychopathy

Narcissism

Machiavellianism

Dark Triad

Mate choice

Long and short-term relationships

\begin{abstract}
A B S T R A C T
Previous research on the Dark Triad traits (i.e., Machiavellianism, psychopathy, and narcissism) has focused solely on the role the Dark Triad traits played in mate choice of actors. The current study $(N=336)$ extends this by manipulating the apparent levels of Dark Triad traits in targets and correlating mate choice in these targets with individual differences in the Dark Triad traits in actors. As expected, both sexes preferred partners low in the Dark Triad traits for long-term mating, while those high in these traits were preferred for one-night stands. However, women high in psychopathy considered the Dark Triad traits in potential male partners more physically attractive and desirable for an one-night stand, as well as a potential husband. Men who were high on psychopathy were likewise attracted to psychopathy in potential mothers. Our findings are discussed from an evolutionary personality paradigm.
\end{abstract}

(c) 2015 Elsevier Ltd. All rights reserved.

\section{Introduction}

Poets, play-writes, philosophers, and professors have spent considerable time, money, and pages in hopes of ascertaining what individuals want in mates and why. Two important observations have emerged. People's personality plays a role in who they select and if they are selected as mates (Rammstedt \& Schupp, 2008). For instance, individuals have mate preference related to a mate's religiousness (Koenig, McGue, \& Iacono, 2009), chronotype (Randler \& Kretz, 2011), and personality (Watson et al., 2004). In the current study we provide new detail about the role of personality traits in mate choice.

One area of personality research that has received considerable recent attention in relation to mating psychology is the work examining the Dark Triad traits (i.e., narcissism, psychopathy, and Machiavellianism). These traits are characterized by entitlement, superiority, dominance (i.e., narcissism), glib social charm, deceit, manipulativeness (i.e., Machiavellianism), erratic, antisocial behavior, impulsivity, and interpersonal antagonism (i.e., psychopathy). The mating psychology associated with these traits tends to be short-term in nature (Jonason, Li, \& Buss, 2010; Jonason, Li, Webster, \& Schmitt, 2009) in both sexes. Evolutionary psychologists have argued these traits might be adaptive because they facilitate fitness-relevant choices/behaviors. There appears

\footnotetext{
* Corresponding author at: School of Social Sciences and Psychology, University of Western Sydney, Milperra, NSW 2214, Australia.

E-mail address: p.jonason@uws.edu.au (P.K. Jonason).
}

to be a mating advantage for men characterized by these traits, at least in the short-term (Jonason et al., 2009; Jonason, Valentine, Li, \& Harbeson, 2011), and women may benefit from having these trait through gene capturing (Carter, Campbell, \& Muncer, 2014; Lyons, Marcinkowska, Helle, \& McGrath, 2015).

However, this work tends to be limited by at least four shortcomings. First, the studies do not always examine men and women simultaneously (Aitken, Lyons, \& Jonason, 2013; Carter et al., 2014). From an evolutionary perspective, participant's sex is an essential variable to consider when studying mate preferences (Buss \& Schmitt, 1993) and psychometrically, having both sexes provides an assessment of relative effects. Second, the studies rarely manipulate potential mate's traits and, instead, tend to rely on descriptive methods. This simply creates a profile of mate preferences. Third, the studies tend to focus on mate preferences or mating psychology (e.g., Jonason, Li et al., 2010) instead of mate choice. It is possible that mate preferences (i.e., who we are attracted to) do not relate to actual mate choice (i.e., who we chose to partner with; Todd, Penke, Fasolo, \& Lenton, 2007). Fourth, researchers tend to examine the role the Dark Triad traits play in mate choice in only one side of the mate choice equation. Researchers have missed the opportunity to examine the role of the Dark Triad traits from both sides. In the present study, we aim to address these limitations using the dating advertisements paradigm.

It is clear that individuals do form relationships with people who are characterized by traits like sensation-seeking (Glicksohn \& Golan, 2001), antisocial behavior (Knight, 2011), and the Dark 
Triad traits (Smith et al., 2014). However, the work tends to rely on established couples. Pre-existing relationships do not allow us to understand mate choice in relation to the Dark Triad traits. First, it is possible that couples feed off each other, changing their personality. Second, it is possible that someone characterized by these traits lied/obscured these aspects of their personality in order to get into a relationship meaning their partner did not actually/ overtly choose someone characterized by these traits.

It is unclear, however, whether the tendencies associated with the Dark Triad traits such as aggression (Keller et al., 2014), social dominance (Jonason, 2015), competitiveness (Jonason, Wee, \& Li, 2015), and a need to be "number 1" (Raskin \& Terry, 1988) will diminish relationship stability thereby decreasing reproductive success in both sexes (Bereczkei \& Csanaky, 1996), or whether dating, especially in the short-term, a likeminded other who enjoys a drama-filled life (Jonason et al., 2011), thriving on the excitement of risk-taking, drug use, and alcohol consumption (Jonason, Koenig, \& Tost, 2010) is preferable. Indeed, there is evidence in support of the former (Smith et al., 2014) and the latter (Keller et al., 2014). In this study, we try to disentangle these.

In addition, there is good reason to think the sex of the participant might be an important factor in understanding mate choice (Buss \& Schmitt, 1993) and the Dark Triad traits (Jonason, Li, \& Czarna, 2013). Men may pay fewer costs and reap more benefits for engaging in risk-taking, including short-term mating which is associated with the Dark Triad traits. Psychopathy may facilitate the most exploitive form of mating among the Dark Triad traits (Jonason, Luévano, \& Adams, 2012), possibly accompanied by cognitive distortions that lead them to mistake a partner who is "good fun" for a "good mom". In contrast, narcissism in men may be accompanied with an implicit desire to reproduce (i.e., "I am so great I should make copies of me"), and consequently be attuned to who would be a good mother, thereby seeing similar women as potential mothering risks and undesirable marriage partners. Indeed, narcissism appears to be linked to a more opportunistic than an exploitive mating strategy (Jonason et al., 2012) and is the most socially desirable and sensitive aspect of the Dark Triad (Rauthmann \& Kolar, 2012).

As men and women have different reproductive psychologies, we would expect women to have different cognitive distortions created by the Dark Triad traits that are constrained by their reproductive realities. Young women (like our sample) may have a preference for "bad boys" as embodied in these traits (Aitken et al., 2013). This preference might not necessarily be a function of psychopathology, but instead, an effect whereby young women who are characterized by these traits are simply not entertained sufficiently by men who are not also high on these traits. This should translate into these women seeing men who are high on the Dark Triad traits-not men likely to commit or to be particularly good long-term investments-as attractive partners, globally. That is, the Dark Triad traits in young women may actually create cognitive distortions in how they evaluate risk in the context of mating, making them believe that sexy "cads" would not only be good for tonight but is the kind of man who would still be there in the morning.

In the current study we document the first data to examine mate choice among actors characterized by the Dark Triad traits in targets who are characterized by the Dark Triad traits using the dating advertisement paradigm. We expect to confirm the primary contention from evolutionary psychologists that the Dark Triad traits prove and advantage in the short-term but not in the long-term mating contexts. We examine how individuals characterized by the Dark Triad traits may structure their romantic/sexual lives.

\section{Method}

\subsection{Participants and procedure}

Participants were 159 female and 177 male volunteers who took part in one of three on-line surveys, advertised as "Personality and dating advertisements" for students at a UK university $(n=70)$, in an on-line participation website $(n=192)$, through a crowdsourcing company $(n=43)$, and via social media advertising $(n=31)$. First, participants were informed about the nature of the study, including relevant ethical issues. Participants were randomly assigned to one of three conditions based on each of the Dark Triad traits. Participants filled in a measure for the Dark Triad, and reported their responses to the target's vignettes that were manipulated to represent the corresponding Dark Triad trait.

\subsection{Measures}

We created 10 dating advertisements that reflected a person who was high or low on the Dark Triad traits; using items from the respective instruments (see Appendix A). In the advertisements, we manipulated characteristics such as cold social attitudes and deceit in line with the Dirty Dozen (Jonason \& Webster, 2010) measure of Machiavellianism (i.e., Machiavellian profiles); leadership, vanity, and self-admiration as in the Narcissistic Personality Inventory (Raskin \& Terry, 1988) measure (i.e., narcissistic profiles); and risk-taking, erratic behavior, and impulsivity as in the Self-Reported Psychopathy (Paulhus, Neumann, \& Hare, 2009) measure (i.e., psychopathic profiles). ${ }^{1}$ Participants rated the profiles for attractiveness as a short-term (viz., physical attractiveness and desirability as a one-night stand) and a long-term (viz., marriage partner and potential father/mother to their future children) partner ( $1=$ not attractive at all; $5=$ extremely attractive). All five advertisements in each category had acceptable-to-good internal consistency (Cronbach's $\alpha$ 's = .69-91).

Participants (Women $n=59, M_{\text {Age }}=24.84, S D_{\text {Age }}=9.84$; Men $n=50, M_{\mathrm{Age}}=25.22, S D_{\mathrm{Age}}=8.57$ ) who rated the Machiavellian opposite-sex advertisements completed the 20-item Mach IV scale (Christie \& Geis, 1970). Participants were asked how much they agreed ( 1 = strongly disagree; 7 = strongly agree) with statements such as: "It is hard to get ahead without cutting corners here and there" and "People suffering from incurable diseases should have the choice of being put painlessly to death." Responses were summed to create an index of Machiavellianism $\left(\alpha_{\text {Women }}=.79\right.$; $\left.\alpha_{\text {Men }}=.56\right)$.

Participants (Women: $n=54, M_{\text {Age }}=25.50, S D_{\text {Age }}=9.70$; Men: $\left.n=72, M_{\text {Age }}=26.14, S D_{\text {Age }}=9.48\right)$ who rated the psychopath opposite-sex advertisements completed the 64-item SRP-III scale (Paulhus et al., 2009). Participants rated how much they agreed ( 1 = strongly disagree; 5 = strongly agree) with statements such as: "I enjoy driving at high speeds" and "I think I could beat a lie detector". Responses were summed to create an index of psychopathy $\left(\alpha_{\text {Women }}=.91 ; \alpha_{\text {Men }}=.90\right)$.

Participants (Women: $n=46, M_{\text {Age }}=22.11, S D_{\text {Age }}=3.79$; Men: $\left.n=55, M_{\text {Age }}=27.78, S D_{\text {Age }}=11.08\right)$ who rated the narcissistic opposite-sex advertisements completed the 40-item Narcissistic Personality Inventory (Raskin \& Terry, 1988). For each item, participants chose one of two statements they felt applied to them more. One statement reflected a narcissistic attitude (e.g., "I have a natural talent for influencing people"), whereas the other did not (e.g., "I am not good at influencing people"). Responses were summed to create an index of their narcissism scores $\left(\alpha_{\text {Women }}=.88 ; \alpha_{\text {Men }}=.86\right)$.

\footnotetext{
1 Similar vignettes were used in prior studies (Aitken et al., 2013; Rauthmann \&
} Kolar, 2012). 


\section{Results}

In order to find out whether men and women showed an overall preference for high or low Dark Triad profiles, we conducted repeated measures ANOVAs for each sex (see Tables 1 and 2 for descriptive statistics). In reference to physical attractiveness, low Machiavellian advertisements were rated higher than high Machiavellian advertisements by both men $(F(1,49)=4.73, p<.04$, $\left.\eta_{\mathrm{p}}^{2}=.09\right)$ and women $\left(F(1,58)=29.23, p<.01, \eta_{\mathrm{p}}^{2}=.34\right)$. Low psychopathy advertisements were rated more attractive than high psychopathy advertisements by men $(F(1,71)=28.22, p<.01$, $\left.\eta_{\mathrm{p}}^{2}=.28\right)$ and women $\left(F(1,53)=7.30, p<.01, \eta_{\mathrm{p}}^{2}=.12\right)$.

For rating desirability as an one night stand, high Machiavellian advertisements were rated higher than the low advertisements by men $\left(F(1,49)=19.57, p<.001, \eta_{\mathrm{p}}^{2}=.28\right)$ and women $(F(1,58)=7.70$, $\left.p<.01, \eta_{\mathrm{p}}^{2}=.12\right)$. Further, high psychopathy advertisements were rated significantly higher than low advertisements by men $\left(F(1,71)=21.90, p<.001, \eta_{\mathrm{p}}^{2}=.24\right)$, and women $(F(1,53)=7.50$, $\left.p<.01, \eta_{\mathrm{p}}^{2}=.12\right)$. Finally, for narcissism, women rated the high advertisements significantly higher than low advertisements as one-night stands $\left(F(1,45)=6.18, p<.01, \eta_{\mathrm{p}}^{2}=.14\right)$.

For rating desirability as a future marriage partner, the low Machiavellian advertisements were rated higher than the high advertisements by men $\left(F(1,49)=179.46, p<.001, \eta_{\mathrm{p}}^{2}=.79\right)$ and women $\left(F(1,58)=224.76, p<.01, \eta_{\mathrm{p}}^{2}=.80\right)$. Further, low psychopathy advertisements were rated as more desirable than the high advertisements by men $\left(F(1,71)=152.00, p<.01, \eta_{\mathrm{p}}^{2}=.68\right)$ and women $\left(F(1,53)=177.80, p<.01, \eta_{\mathrm{p}}^{2}=.77\right)$. Finally, the low narcissistic advertisements were rated as more desirable marriage partners by women $\left(F(1,45)=44.01, \quad p<.01, \eta_{\mathrm{p}}^{2}=.49\right)$ and men $\left(F(1,53)=19.92, p<.01, \eta_{\mathrm{p}}^{2}=.12\right)$.

For rating desirability as a future mother or father of the participants children, low Machiavellian advertisements were rated higher than the high advertisements by men $(F(1,49)=179.46$, $\left.p<.001, \eta_{\mathrm{p}}^{2}=.79\right)$ and women $\left(F(1,58)=234.97, p<.01, \eta_{\mathrm{p}}^{2}=.80\right)$. Further, the low psychopathy advertisements were rated higher than the high advertisements by men $(F(1,71)=172.21, p<.001$, $\left.\eta_{\mathrm{p}}^{2}=.71\right)$ and women $\left(F(1,53)=162.00, p<.01, \eta_{\mathrm{p}}^{2}=.75\right)$. Finally, the low narcissistic advertisements were rated as more desirable future fathers $\left(F(1,45)=45.00, p<.01, \eta_{\mathrm{p}}^{2}=.50\right)$ and mothers $\left(F(1,54)=11.82, p<.01, \eta_{\mathrm{p}}^{2}=.18\right)$.

In order to test whether the Dark Triad traits in actors predicted mate choice in hypothetical targets characterized by the Dark Triad traits, we conducted cross-correlations between ratings for high and low advertisements in different mating contexts (see Tables 3 and 4). As an adjustment for Type I error inflation, we lowered the accepted $p$-value to .01 , resulting in five effects in women and one in men; two in the short-term mating context. Machiavellianism in women was associated ratings men who were characterized as Machiavellian as good future marriage partners. The correlation between women's psychopathy scores and ratings of the physical attractiveness, desirability as a marriage partner, and quality as a father for high psychopathy advertisements was significantly greater than the low psychopathy advertisement. And last, men high in psychopathy felt target-women high in psychopathy would be good mother and marriage partner.

Few correlations differed as a function of participant's sex. Narcissism in men correlated with lower scores, and in women, with higher scores when rating narcissist advertisements as marriage partners (Fisher's $z=-2.90, p<.001$ ). Further, narcissism in men was related to rating high advertisements as less desirable mothers, and in women, as more desirable fathers $(z=-3.31, p<.001)$.

\section{Discussion}

In this study, we provided a unique assessment of the role the Dark Triad traits play in mate choice from the position of the actor and the target simultaneously. Prior work on the role the Dark Triad traits play in mating psychology have focused on existing couples (Smith et al., 2014), other aspects of mating psychology (e.g., mate retention; Jonason, Li et al., 2010), or on mate preferences (Jonason et al., 2011). As mate choice might differ from mate preferences (Todd et al., 2007), we wanted to ascertain whether those characterized by the Dark Triad traits actively choose homogamous partners. Importantly, we examined mate choice from the perspective of evolutionary personality psychology to better understand the adaptive value of these traits (Jonason et al., 2009). We examined the participant's sex and the temporal context of the relationship to understand the apparently paradoxical effect of choosing a mate who embodies the Dark Triad traits.

In confirmation of the context-specific value of the Dark Triad traits suggested by evolutionary psychologists (Jonason et al., 2009, 2011), both sexes found advertisements with low levels of the traits more desirable as spouses, and advertisements with high levels of the traits as more desirable one-night stand partners. Long-term partnerships are characterized by high levels of mutual investment (Buss \& Schmitt, 1993), essential for bi-parental care (Fisher, 1994), which may require ongoing amicability. Both sexes benefit from this exchange and, therefore, similarly invest in making a good choice in such a partner. This is no surprise as the adaptive challenges in bi-parental care are similar for both men and women. Interestingly, however, people felt those high in psychopathy and Machiavellianism were less attractive than those low in the traits. This may be because there is contamination in judgments of physical attractiveness by personality traits.

It is noteworthy we found relatively limited evidence that people high in the Dark Triad traits chose mates with a similar personality. Associations were localized to psychopathy over the other traits and few of these were in the short-term context. This may be because Machiavellianism plays a limited role in mating psychology, whereas narcissism is associated with a different form

Table 1

Descriptive statistics for women's ratings of low and high Dark Triad male advertisements in different mating contexts.

\begin{tabular}{|c|c|c|c|c|c|c|}
\hline & \multicolumn{6}{|l|}{ Mean (SD) } \\
\hline & \multicolumn{2}{|c|}{ Machiavellianism } & \multicolumn{2}{|l|}{ Psychopathy } & \multicolumn{2}{|l|}{ Narcissism } \\
\hline & Low & High & Low & High & Low & High \\
\hline \multicolumn{7}{|l|}{ Short-term mating } \\
\hline Attraction & $3.50(0.88)$ & $2.62(0.94)^{\mathrm{a}}$ & $2.82(0.83)$ & $2.37(0.92)^{a}$ & $2.76(0.68)$ & $2.61(0.96)$ \\
\hline One night stand & $2.02(0.84)$ & $2.47(1.11)^{\mathrm{a}}$ & $2.10(0.81)$ & $2.46(1.74)^{\mathrm{a}}$ & $2.00(0.81)$ & $2.47(1.09)^{\mathrm{a}}$ \\
\hline \multicolumn{7}{|l|}{ Long-term mating } \\
\hline Marriage partner & $3.87(0.84)$ & $1.74(0.61)^{\mathrm{a}}$ & $3.30(0.84)$ & $1.41(0.53)^{a}$ & $2.96(0.78)$ & $1.87(0.71)^{\mathrm{a}}$ \\
\hline Father & $3.66(0.96)$ & $1.57(0.56)^{a}$ & $3.18(0.93)$ & $1.30(0.47)^{\mathrm{a}}$ & $2.88(0.80)$ & $1.80(0.77)^{a}$ \\
\hline
\end{tabular}

a Significant difference between the low and high advertisements, $p<.01$. 
Table 2

Descriptive statistics for men's ratings of low and high Dark Triad female advertisements in different mating contexts.

\begin{tabular}{|c|c|c|c|c|c|c|}
\hline & \multicolumn{6}{|l|}{ Mean (SD) } \\
\hline & \multicolumn{2}{|c|}{ Machiavellianism } & \multicolumn{2}{|l|}{ Psychopathy } & \multicolumn{2}{|l|}{ Narcissism } \\
\hline & Low & High & Low & High & Low & High \\
\hline \multicolumn{7}{|l|}{ Short-term mating } \\
\hline Attraction & $3.53(0.72)$ & $3.18(0.98)^{\mathrm{a}}$ & $3.24(0.80)$ & $2.70(0.86)^{\mathrm{a}}$ & $2.76(0.68)$ & $2.61(0.96)$ \\
\hline One night stand & $2.69(0.89)$ & $3.43(0.96)^{\mathrm{a}}$ & $2.56(0.90)$ & $3.10(1.02)^{a}$ & $2.00(0.81)$ & 2.47 (1.09) \\
\hline \multicolumn{7}{|l|}{ Long-term mating } \\
\hline Marriage partner & $3.86(0.61)$ & $2.12(0.75)^{\mathrm{a}}$ & $3.45(0.84)$ & $1.79(0.64)^{\mathrm{a}}$ & $2.96(0.78)$ & $1.87(0.71)^{a}$ \\
\hline Parent & $3.74(0.68)$ & $2.02(0.74)^{\mathrm{a}}$ & $3.34(0.74)$ & $1.71(0.79)^{\mathrm{a}}$ & $2.88(0.80)$ & $1.80(0.77)^{\mathrm{a}}$ \\
\hline
\end{tabular}

a Significant difference between the low and high advertisements, $p<.01$.

Table 3

Correlations between women's Dark Triad scores and ratings of men's advertisements.

\begin{tabular}{|c|c|c|c|c|c|c|c|c|c|}
\hline & \multicolumn{3}{|c|}{ Psychopathy } & \multicolumn{3}{|c|}{ Machiavellianism } & \multicolumn{3}{|c|}{ Narcissism } \\
\hline & High & Low & $z$ & High & Low & $z$ & High & Low & $z$ \\
\hline Attractiveness & $.39^{*}$ & $-.33^{*}$ & $3.94^{*}$ & .24 & -.28 & $2.87^{* *}$ & .04 & -.02 & 1.13 \\
\hline One-night stand & $.39^{* * *}$ & .18 & 1.14 & .25 & -.04 & 1.57 & .01 & .10 & -0.41 \\
\hline Marriage & $.43^{* * *}$ & -.21 & $3.48^{* *}$ & $.41^{* * *}$ & -.30 & $4.07^{* *}$ & .24 & -.18 & $2.00^{*}$ \\
\hline Parent & $.35^{* * *}$ & -.18 & $2.81^{* *}$ & .25 & -.28 & $2.93^{* * *}$ & .30 & -.14 & $2.11^{*}$ \\
\hline
\end{tabular}

Note: $z$ is Steiger's $z$ to compare dependent correlations.

* $p<.05$.

*** $p<.01$.

Table 4

Correlations between men's Dark Triad scores and ratings of women's advertisements.

\begin{tabular}{|c|c|c|c|c|c|c|c|c|c|}
\hline & \multicolumn{3}{|c|}{ Psychopathy } & \multicolumn{3}{|c|}{ Machiavellianism } & \multicolumn{3}{|c|}{ Narcissism } \\
\hline & High & Low & $z$ & High & Low & $z$ & High & Low & $z$ \\
\hline Attractiveness & $.29^{*}$ & -.02 & $1.87^{*}$ & .13 & -.13 & -1.34 & -.22 & .06 & -1.38 \\
\hline One-night stand & .16 & $.30^{*}$ & -0.86 & .04 & -.03 & 0.36 & -.33 & -.29 & -0.21 \\
\hline Marriage & $.39^{* *}$ & $-.27^{*}$ & $3.52^{* *}$ & .20 & -.08 & 1.45 & $-.36^{*}$ & .19 & $-2.81^{*}$ \\
\hline Parent & $.36^{* *}$ & $-.29^{*}$ & $4.07^{* *}$ & .22 & -.06 & 1.44 & $-.37^{*}$ & .17 & $-2.76^{*}$ \\
\hline
\end{tabular}

Note: $z$ is Steiger's $z$ to compare dependent correlations.

* $p<.05$.

$p<.01$.

of mating psychology than psychopathy which may not be sensitive to the information we provided or may not drive a particularly choosy mating psychology (Jonason et al., 2012). Nevertheless, in women, psychopathy correlated with greater liking of men high on psychopathy in both long and short-term relationships. It is possible that women who are high in these traits mistake "sexy cads" for "good dads". Such cognitive distortions have been previously found, during ovulation, when women have increased sex-drive and a desire for masculinized partners (Durante, Griskevicius, Simpson, Cantú, \& Li, 2012). Similarly, men high in psychopathy also rated high psychopathy advertisements as desirable mothers. As it is likely that a man high on psychopathy will simply abandon his children, he may need to believe that she will be a good mother even when evidence is lacking. This may act as an insurance policy for his mate-defecting ways (Jonason, Li et al., 2010). Nevertheless, there clearly is need for more research on how the Dark Triad relates to long-term relationships and parenting in both sexes. Cold, manipulative parents could have long-term developmental consequences for the offspring, and may partially explain Dark Triad traits in adulthood.

Beyond evolutionary considerations of ultimate explanations, it is worth noting proximate mechanistic explanations for our effects. Superficially, why would anyone want to date or have sex with someone who was such an apparent risk? We contend homogamous mate choice on personality may translate into homogamous mate choice in lifestyles or at least preferred lifestyles. Someone characterized by the Dark Triad traits may enjoy excitement, volatility (Jonason et al., 2011), drug use, and alcohol (Jonason, Koenig et al., 2010) and, thus, may prefer partners who live a similar lifestyle as they do. Imagine the conservative trying to date the quintessential party boy/girl. They not only have different personality traits but, if we accept that personality traits facilitate the creation of preferred niches (Jonason et al., 2014), these two people prefer nearly orthogonal lifestyles; the former waking up to go to Church at the same time the latter arrives home after a night of partying.

\section{Limitations and conclusions}

The current study has a number of limitations. First, we did not examine the lower-order factors of narcissism and psychopathy (Jonason, Jones, \& Lyons, 2013) as we had no particular predictions in that regard. Second, we exclusively used self-report measures (but see, Haeffel \& Howard, 2010). Third, we relied on a WEIRD sample (i.e., Western, Educated, Industrialized, and Democratic; Henrich, Heine, \& Norenzayan, 2010). Fourth, ovulation may play a role in mate choice for those high in the Dark Triad, but we failed to assess ovulation. We may have tapped trait cognitive biases whereas work in ovulation may tap state biases. Future research integrating ovulation effects and personality psychology is warranted. For instance, it is possible the factors shift during ovulation are personality traits like the Dark Triad which facilitate greater 
risk-taking in life and love. Fifth, we used normative assessments of mate choice, but this may not accurately reflect the constrained choices in reality (Jonason et al., 2011). Fifth, we may have suffered some diminished power. While we found few significant correlations in Tables 3 and 4, our goal was to test moderation more than anything else and, thus, we feel this concern is not overly problematic. Nevertheless, we have advanced the science of the Dark Triad traits and assortative mating with the dating advertisement paradigm.

An age-old question is whether birds of a feather flock together or do opposites attract. The answer appears to depend on what trait, sex, and mating context one is considering. Using an evolutionary paradigm, we have provided some resolution to question of mate choice in relation to the Dark Triad traits. Importantly, we have documented how and potentially why people may, or may not, date, marry, or have sex with those characterized by "dark" aspects of personality.

\section{Appendix A. Dating advertisement examples}

\section{A.1. Low psychopathy}

Meet John/Kate, s/he describes him/herself as:

Someone who plays it safe and plans for the future. S/he feels it is very important to delay gratification today to get what $s /$ he wants and needs in the future. S/he enjoys stability over all things.

\section{A.2. High psychopathy}

Meet Josh/Laura, s/he describes him/herself as:

Impulsive, a sensation-seeker, and someone who lives in the "now". S/he enjoys risky activities where s/he can get a rush like driving fast, drinking alcohol, and partying. S/he abhors monotony and changes jobs often.

\section{A.3. Low Machiavellianism}

Meet Jack/Anne, s/he describes him/herself as:

Someone who is a team player. S/he enjoys being a small cog in a large machine, and claims $\mathrm{s} /$ he always speaks the truth. $\mathrm{S} /$ he would never say something he doesn't believe just to get ahead of the crowd.

\section{A.4. High Machiavellianism}

Meet Jonny/Julie, s/he describes him/herself as:

A person who is not afraid to offend a few people on his way. S/ he speaks his/her mind but also says s/he's happy to conceal some truths if beneficial in the long run. S/he is someone who could talk his/her way out of any situation by using charm and flattery.

\section{A.5. Low narcissism}

Meet Steven/Lorna, s/he describes him/herself as:

Somebody who is not interested in new advertisements or fashions. $\mathrm{S} /$ he thinks $\mathrm{s} /$ he is no better or worse than other people, and that $s /$ he would prefer to blend in with the crowd rather than stand out. S/he is essentially a modest person.

\section{A.6. High narcissism}

Meet Josh/Julie, s/he describes him/herself as:

Somebody who is very assertive, and rarely depends on others to get things done. $\mathrm{S} /$ he likes to be complemented, and likes to look at him/herself in the mirror. S/he likes starting new fashions rather than simply following them.

\section{References}

Aitken, S. J., Lyons, M., \& Jonason, P. K. (2013). Dads or cads? Women's strategic decisions in the mating game. Personality and Individual Differences, 55, $118-122$.

Bereczkei, T., \& Csanaky, A. (1996). Mate choice, marital success, and reproduction in a modern society. Ethology and Sociobiology, 17, 17-35.

Buss, D. M., \& Schmitt, D. P. (1993). Sexual strategies theory: An evolutionary perspective on human mating. Psychological Review, 100, 204-232.

Carter, G. L., Campbell, A. C., \& Muncer, S. (2014). The Dark Triad of personality: Attractiveness to women. Personality and Individual Differences, 56, 57-61.

Durante, K. M., Griskevicius, V., Simpson, J. A., Cantú, S. M., \& Li, N. P. (2012). Ovulation leads women to perceive sexy cads as good dads. Journal of Personality and Social Psychology, 103, 292-305.

Fisher, H. (1994). The anatomy of love. New York, NY: Ballantine Books.

Glicksohn, J., \& Golan, H. (2001). Personality, cognitive style, and assortative mating. Personality and Individual Differences, 30, 1199-1209.

Haeffel, G. J., \& Howard, G. S. (2010). Self-report: Psychology's four-letter word. American Journal of Psychology, 123, 181-188.

Henrich, J., Heine, S. J., \& Norenzayan, A. (2010). The weirdest people in the world? Behavioral and Brain Sciences, 33, 61-83.

Jonason, P. K. (2015). How "dark" personality traits and perceptions come together to predict racism in Australia. Personality and Individual Differences, 72, 47-51.

Jonason, P. K., Jones, A., \& Lyons, M. (2013). Creatures of the night: Chronotypes and the Dark Triad traits. Personality and Individual Differences, 55, 538-541.

Jonason, P. K., Koenig, B. L., \& Tost, J. (2010). Living a fast life. Human Nature, 21, $428-442$.

Jonason, P. K., Li, N. P., \& Buss, D. M. (2010). The costs and benefits of the Dark Triad: Implications for mate poaching and mate retention tactics. Personality and Individual Differences, 48, 373-378.

Jonason, P. K., Li, N. P., \& Czarna, A. Z. (2013). Quick and dirty: Some psychosocial costs associated with the Dark Triad in three countries, 11, 172-185.

Jonason, P. K., Li, N. P., Webster, G. W., \& Schmitt, D. P. (2009). The Dark Triad: Facilitating short-term mating in men. European Journal of Personality, 23, 5-18.

Jonason, P. K., Luévano, V. X., \& Adams, H. M. (2012). How the Dark Triad traits predict relationship choices. Personality and Individual Differences, 53, 180-184.

Jonason, P. K., Valentine, K. A., Li, N. P., \& Harbeson, C. L. (2011). Mate-selection and the Dark Triad: Facilitating a short-term mating strategy and creating a volatile environment. Personality and Individual Differences, 51, 759-763.

Jonason, P. K., \& Webster, G. D. (2010). The Dirty Dozen: A concise measure of the Dark Triad. Psychological Assessment, 22, 420-432.

Jonason, P. K., Wee, S., \& Li, N. P. (2015). Competition, autonomy, and prestige: Mechanisms through which the Dark Triad predict job satisfaction. Personality and Individual Differences, 72, 112-116.

Keller, P. S., Blincoe, S., Gilbert, L. R., DeWall, C. N., Haak, E. A., \& Widiger, T. (2014) Narcissism in romantic relationships: A dyadic perspective. Journal of Social and Clinical Psychology, 33, 25-50.

Knight, K. E. (2011). Assortative mating and partner influence on antisocial behavior across the life course. Journal of Family Theory E Review, 3, 198-219.

Koenig, L. B., McGue, M., \& Iacono, W. G. (2009). Rearing environmental influences on religiousness: An investigation of adolescent adoptees. Personality and Individual Differences, 47, 652-656.

Lyons, M. T., Marcinkowska, U. M., Helle, S., \& McGrath, L. (2015). Mirror, mirror, on the wall, who is the most masculine of them all? The Dark Triad, masculinity and women's mate choice. Personality and Individual Differences, 74, 153-158.

Paulhus, D. L., Neumann, C. S., \& Hare, R. D. (2009). Manual for the Self-Report Psychopathy scale. Toronto, Ontario: Multi-Health Systems.

Rammstedt, B., \& Schupp, J. (2008). Only the congruent survive-Personality similarities in couples. Personality and Individual Differences, 45, 533-535.

Randler, C., \& Kretz, S. (2011). Assortative mating in morningness and eveningness. International Journal of Psychology, 46, 91-96.

Raskin, R., \& Terry, H. (1988). A principal-components analysis of the narcissistic personality inventory and further evidence of its construct validity. Journal of Personality and Social Psychology, 54, 890-902.

Rauthmann, J. F., \& Kolar, G. P. (2012). How "dark" are the Dark Triad traits? Examining perceived darkness of narcissism, Machiavellianism, and psychopathy. Personality and Individual Differences, 53, 884-889.

Smith, C., Hadden, B. W., Webster, G. D., Jonason, P. K., Gesselman, A. N., \& Crysel, L. C. (2014). Mutually attracted or repulsed? Actor-partner interdependence models of Dark Triad traits and relationship outcomes. Personality and Individual Differences, 67, 35-41.

Todd, P. M., Penke, L., Fasolo, B., \& Lenton, A. P. (2007). Different cognitive processes underlie human mate choices and mate preferences. Proceedings of the National Academy of Sciences, 104, 15011-15016.

Watson, D., Klohnen, E. C., Casillas, A., Nus Simms, E., Haig, J., \& Berry, D. S. (2004), Match makers and deal breakers: Analyses of assortative mating in newlywed couples. Journal of Personality, 72, 1029-1068. 